\title{
Aerospace Meteorology: An Overview of Some Key Environmental Elements
}

\author{
William W. Vaughan', Dale L. Johnson²
}

\begin{abstract}
The natural terrestrial environment plays a significant role in the design and operation of aerospace vehicles (space vehicles and rockets) and in the associated integrity of aerospace systems and elements. Addressed herein are some of the key vehicle and environment areas of concern plus "lessons learned" that have been identified over a number of years. Many of these aerospace meteorology related events occurred during the development and interpretation of natural environment inputs, especially those of terrestrial environment, used in the design and development of the Saturn Apollo and Space Shuttle vehicles plus associated mission operations. Background is given regarding the actions needed to avoid having to re-learn these lessons.
\end{abstract}

KEYWORDS: Aerospace meteorology, Launch vehicle development, Mission operations.

\section{INTRODUCTION}

This paper is primarily based on and reflects the content of the recent revision conducted by the authors and their colleagues of the report "Terrestrial Environment (Climatic) Criteria Guidelines for Use in Aerospace Vehicle Development" (Johnson, 2008). The Earth's terrestrial environment is typically defined as the altitude region up to approximately $90 \mathrm{~km}$. Aerospace vehicle design guidelines are provided in the report for the following: winds; atmospheric models and thermodynamic properties; thermal radiation; U.S. and world surface extremes; humidity; precipitation, fog, and icing; cloud phenomena and cloud cover models; atmospheric electricity; atmospheric constituents; aerospace vehicle exhaust and toxic chemical release; tornadoes and hurricanes; geologic hazards; and sea state. Also included is information on mission analysis, prelaunch monitoring, flight evaluation, physical constants, and metric/English unit conversion factors. The first version of this report was published in 1962 and has subsequently been updated periodically by the NASA Marshall Space Flight Center. The terrestrial environment guidelines provided in the report are intended to be used in the development of specific terrestrial environment design requirements based on an aerospace vehicle's mission requirements and on the program's engineering design philosophy.

These terrestrial environment criteria guidelines were formulated based on discussions with and requests from engineers who were involved in aerospace vehicle design, development and operations. Therefore, they represent responses to actual engineering problems and are not just a general compilation of environmental data. NASA Centers, various other government agencies, and their associated 
contractors responsible for the design, mission planning, and operational studies have used these guidelines, and associated design requirements developed from them, extensively.

Another key document related to the scope of this paper is the "Guide to Reference and Standard Atmosphere Models" (Vaughan, 2010). This document contains the description of over 75 reference and standard atmosphere models, Earth and planetary, prepared by national and international organizations. It provides information on the scope, data bases, uncertainty, sources for codes, and applicable references. It was prepared based on the contributions of numerous authors. The objective of the guide is to enable the reader to more readily ascertain the applicability of a model for their intended use.

Another element of aerospace meteorology, weather support, is reviewed in relation to the Space Shuttle operations by Bellue et al. (2006). The mission's success and safety of aerospace vehicles present unique weather support challenges. Weather support requirements to ensure the safe processing, launch, and landing of these vehicles have been continuously improved since the first successful missile launches. Weather equipment for operational support has also significantly improved since these first launches. The effective use of weather information is translated both into significant annual cost savings through the timely management decisions, and into paramount contributions to safety.

Ideally, aerospace vehicle design should accommodate all expected operational terrestrial environment conditions. However, this is neither economically nor technically feasible. For this reason, consideration must be given to the protection of the vehicle from some extremes by use of support equipment, special facilities, and specialized forecast personnel to advise on the expected occurrence of critical terrestrial environment conditions. Services of specialized weather forecast personnel have proved very economical in comparison to a more extensive vehicle design that would be necessary to cope with all terrestrial environment possibilities.

In general, terrestrial environment design requirement documents do not specify how the designer should use the data. Such specifications may be established only through analysis and study of a particular design problem.

\section{ENGINEERING RELIVANCE}

All aerospace vehicles (launch vehicle and spacecraft) have one thing in common. To one degree or another, they must be designed to accommodate the expected operational mission requirements relative to the terrestrial environment. Thus, terrestrial environment phenomena and elements play a significant role in how aerospace vehicles are designed and operated and in protecting the integrity of their systems and components (Vaughan et al., 1997). It is important to recognize the need to define the terrestrial environment design requirements very early in the design and development cycle of any new or to be modified aerospace vehicle in order for the vehicles to meet their mission operational requirements. Table 1 provides an overview of the key engineering systems and terrestrial environment interactions relative to vehicle engineering systems and mission phase.

Specific definitions of the terrestrial environment can be provided which, if the aerospace vehicle is designed to accommodate, will enable the desired operational capability within the defined design risk level. It is very important that those responsible for the terrestrial environment definitions for use in the design of an aerospace vehicle have a close working relationship with program management and design engineers. This will ensure that the desired operational capabilities are reflected in the terrestrial environment requirements specified for design and development of the vehicle and, accordingly, their interpretation relative to engineering applications.

An aerospace vehicle's response to terrestrial environment design criteria must be carefully evaluated in order to provide an acceptable design relative to the desired operational requirements. The choice of criteria depends on the specific launch and landing location(s), vehicle configuration, and expected mission plan(s). Vehicle design, operation, and flight procedures can be separated into particular categories for proper assessment of environmental influences and impact on the life history of each vehicle and all associated systems. These categories include: (1) purpose and concept of the vehicle, (2) preliminary engineering design, (3) structural design, (4) control system design, (5) flight mechanics, orbital mechanics, and performance (trajectory shaping), (6) optimization of design limits regarding the various natural environmental factors, and (7) final assessment of the terrestrial environmental capability for launch and flight operations.

Another important matter that must be recognized is the necessity to have a coordinated and consistent set of terrestrial environment requirements to be used in a new aerospace vehicle's design and development or modification 
Table 1. Key Terrestrial Environment Parameters Needed versus Engineering Systems $(X)$ and Mission Phase (P).

\begin{tabular}{|c|c|c|c|c|c|c|c|c|c|c|c|c|}
\hline $\mathbf{X}$ & \multicolumn{11}{|c|}{ Terrestrial Environment Parameters } & \multirow{2}{*}{$\begin{array}{l}P \\
\end{array}$} \\
\hline 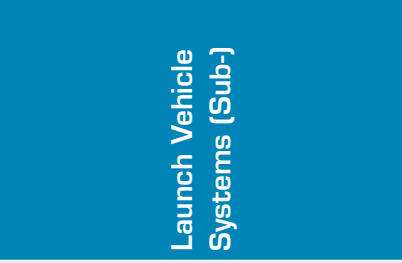 & 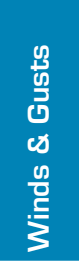 & 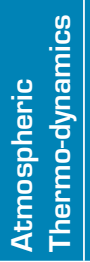 & 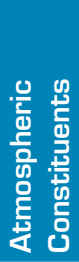 & 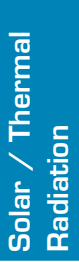 & 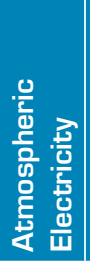 & $\begin{array}{l}\text { 웅 } \\
\text { ø } \\
\text { 욤 } \\
\frac{0}{0}\end{array}$ & $\begin{array}{l}\text { 흠 } \\
\text { 를 } \\
\text { 도 }\end{array}$ & 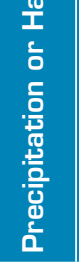 & 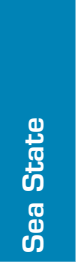 & 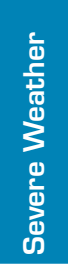 & 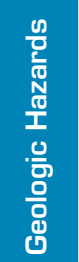 & \\
\hline System & $\mathrm{X} \mathrm{P}$ & X P & X P & X P & $\mathrm{X} \mathrm{P}$ & X P & $\mathrm{X} P$ & $\mathrm{X} P$ & $\mathrm{X} P$ & X P & $\mathrm{X}$ & Mission Analysis \\
\hline Propulsion Engine Sizing & $\mathrm{X}$ & X P & $\mathrm{P}$ & & $\mathrm{X}$ & & X P & & & $\mathrm{X}$ & & Manufacturing \\
\hline Structures / Airframe & X P & X P & & $\mathrm{X}$ & X P & & $\mathrm{P}$ & X P & $\mathrm{X}$ & X P & $\mathrm{P}$ & Testing \\
\hline $\begin{array}{l}\text { Performance / Trajectory/ } \\
\text { G \& N }\end{array}$ & X P & X P & $\mathrm{P}$ & $\mathrm{P}$ & $\mathrm{X} \mathrm{P}$ & $\mathrm{P}$ & $\mathrm{P}$ & $\mathrm{P}$ & $\mathrm{P}$ & $\mathrm{P}$ & $\mathrm{P}$ & $\begin{array}{l}\text { Transportation / } \\
\text { Ground Handling }\end{array}$ \\
\hline Aerodynamics & X P & X P & $\mathrm{P}$ & $\mathrm{P}$ & $\mathrm{P}$ & & $\mathrm{P}$ & $\mathrm{P}$ & $\mathrm{P}$ & $\mathrm{P}$ & & Roll Out / On Pad \\
\hline $\begin{array}{l}\text { Thermal Loads / } \\
\text { Aerodynamic Heat }\end{array}$ & X P & X P & $\mathrm{P}$ & X P & $\mathrm{P}$ & $\mathrm{P}$ & $\mathrm{P}$ & $\mathrm{P}$ & $\mathrm{P}$ & $\mathrm{P}$ & & $\begin{array}{l}\text { Pre-Launch / } \\
\text { DOL Count }\end{array}$ \\
\hline Control & X P & X P & $\mathrm{P}$ & $\mathrm{P}$ & X P & $\mathrm{P}$ & $\mathrm{P}$ & $\mathrm{P}$ & & X P & & Liftoff / Ascent \\
\hline Loads & X P & X P & & & $\mathrm{P}$ & $\mathrm{P}$ & & $\mathrm{P}$ & X P & X P & & Stages Recovery \\
\hline Avionics & $\mathrm{P}$ & $\mathrm{P}$ & $\mathrm{X}$ & $\mathrm{X}$ & X P & $\mathrm{P}$ & $\mathrm{X}$ & $\mathrm{P}$ & & X P & & Flight \\
\hline Materials & $\mathrm{X}$ & X P & X P & X P & $\mathrm{X}$ & & $\mathrm{X}$ & $\mathrm{X}$ & $\mathrm{X}$ & $\mathrm{X}$ & & Orbital \\
\hline Electric Power & $\mathrm{P}$ & $\mathrm{P}$ & $\mathrm{X}$ & & X P & $\mathrm{X}$ & & X P & & $\mathrm{P}$ & & Descent \\
\hline Optics & $\mathrm{P}$ & X P & X P & $\mathrm{X}$ & $\mathrm{P}$ & X P & $\mathrm{P}$ & X P & $\mathrm{P}$ & $\mathrm{P}$ & & Landing \\
\hline Thermal Control & $\mathrm{P}$ & X P & $\mathrm{P}$ & X P & $\mathrm{P}$ & & $\mathrm{P}$ & X P & $\mathrm{P}$ & $\mathrm{P}$ & & Post Landing \\
\hline Telemetry / Tracking / Comms & $\mathrm{P}$ & X P & X P & $\mathrm{P}$ & X P & X P & $\mathrm{P}$ & X P & $\mathrm{P}$ & X P & $\mathrm{P}$ & Ferry / Transport \\
\hline & $\mathrm{P}$ & & & & $\mathrm{P}$ & & $\mathrm{P}$ & $\mathrm{P}$ & & $\mathrm{P}$ & $\mathrm{P}$ & Facility / Special Eq \\
\hline & $\mathrm{P}$ & $\mathrm{P}$ & $\mathrm{P}$ & & $\mathrm{P}$ & & $\mathrm{P}$ & $\mathrm{P}$ & & & $\mathrm{P}$ & Refurbishment \\
\hline Mission Operations & X P & X P & X P & X P & X P & $\mathrm{X}$ & $\mathrm{XP}$ & $\mathrm{X} \mathrm{P}$ & $\mathrm{X}$ & X P & X P & Storage \\
\hline
\end{tabular}

of an existing vehicle. This is particularly important when diverse groups are involved in the development, and is of utmost importance for any international endeavor. A "central control point" holding responsibility for the definition and interpretation of the natural environment inputs is critical to the successful design and operation of any new or modified aerospace vehicle. Without this control, different terrestrial environment values or models may be used with costly results in terms of money, time, and vehicle performance. This central control point should also include responsibility for terrestrial environment inputs related to mission analysis, test support requirements, flight evaluation, launch constraints, and operational support.

The close association between the design and test engineering groups and those responsible (central control point) for the terrestrial environment inputs is key to the success of the vehicle's development process. This procedure has been followed in many NASA aerospace vehicle developments and is of particular importance for any new aerospace vehicle. Feedback is critical for the vehicle development process relative to terrestrial environment requirements and thus the ability to produce a viable vehicle design and operational capability.

Finally, although often not considered to be significant, it is very important that all aerospace vehicle design review meetings include a representative from the natural environment group (central control point) assigned to support the program. This will ensure the good understanding of design requirements and timely opportunity to incorporate terrestrial environment inputs and interpretations, which are tailored to the desired operational objectives into the design process. It is also necessary that any proposed deviations from the specified terrestrial environment design requirements, including those used in preliminary design tradeoff studies, be approved by the responsible terrestrial environment central control point. This will ensure that all program elements are using the same baseline terrestrial environment inputs. Included is the need for the maintenance of a centralized and 
controlled terrestrial environment definition document. This is also important in order to make sure that the program manager understands the operational impact of any change in terrestrial environment requirements before they are implemented into the design. Otherwise, gross errors and deficiencies in design, and thus operational capability, may result from using different inputs selected from various sources.

One must remember that the flight profile of any aerospace vehicle includes travel through the terrestrial environment. Terrestrial environment definitions are usually limited to information below $\approx 90 \mathrm{~km}(\approx 295,000 \mathrm{ft})$. Thus, aerospace vehicle operations will always be influenced to some degree by the terrestrial environment with which they interact. As a result, the definition of the terrestrial environment and its interpretation is one of the most important aerospace vehicle design and development inputs. The definition plays a significant role in the areas of structures, control systems, trajectory shaping (performance), aerodynamic heating, and takeoff/landing capabilities. The aerospace vehicle's capabilities which result from the design, in turn, determine the constraints and flight opportunities for tests and mission operations.

\section{SOME TERRESTRIAL ENVIRONMENT CONSIDERATIONS}

Experience gained and lessons learned from developing terrestrial environment design criteria for previous aerospace vehicle programs have proven that, in order to be most effective, the terrestrial environment design criteria for a new vehicle should: (1) Be developed once the mission is defined, in order to ensure the desired operational performance of the aerospace vehicle.

(2) Be issued under the signature of the program manager and be part of the controlled program definition and requirement documentations.

(3) Specify terrestrial environment requirements for all phases of activity including prelaunch, launch, ascent, on-orbit, descent, and landing.

For extremes in the terrestrial environments, there generally is no known physical upper or lower bound. However, wind speed does have a strict physical lower bound of zero. Essentially, all observed extreme conditions have a finite probability of being exceeded. Consequently, terrestrial environment extremes used to develop design requirements must be accepted with the knowledge that there is some risk of the values being exceeded. The measurement of many environmental parameters may not be as accurate as desired. Also, in some cases theoretical model estimates are believed to be of more value for design than those indicated by empirical distributions from short periods of record. Therefore, theoretical values are given considerable weight when selecting extreme values for some parameters; e.g., peak surface winds. Criteria guidelines are normally presented for various percentiles based on the available data. There should be caution in the interpretation of these percentiles in aerospace vehicle studies to ensure consistency with physical reality and the specific design and operational problems of concern.

Aerospace vehicles are not normally designed for launch and flight in severe weather conditions such as hurricanes, thunderstorms, ice storms, and squalls. Environmental elements associated with severe weather that may be hazardous to aerospace vehicles and associated ground support equipment include strong ground and in-flight winds, strong wind shears and gusts, turbulence, icing conditions, and electrical activity. Terrestrial environment guidelines should provide information concerning those severe weather characteristics that should be included in vehicle and associated facilities of design necessities and specifications, if required to meet the program's mission operational requirements.

Knowledge of the terrestrial environment is also necessary to establish test requirements for aerospace vehicles and in the design of associated support equipment and facilities. Such data are required to define fabrication, storage, transportation, test, and preflight design conditions, and should be considered for both the whole vehicle system and the components which comprise the system.

The group with the central control point responsibility and authority to define and interpret terrestrial environment design requirements must also be in a position to pursue environment input-related applied research studies and engineering assessments and updates. This is necessary to ensure accurate and timely terrestrial environment inputs tailored to the program's needs. Design engineers and program managers should not assume they can simply draw on the vast statistical databases and numerous models of the terrestrial environment currently available in literature without interpretation and tailoring to specific vehicle design needs. Otherwise, this can prove to be a major deterrent to the successful development and operation of an aerospace vehicle.

Although vehicle design ideally should accommodate all expected operational environment conditions, it is neither 
economically nor technically feasible to design an aerospace vehicle to withstand all terrestrial environment extremes. For this reason, consideration should be given to protecting vehicles from some situations. This can be achieved by using support equipment and specialized weather forecast personnel to provide advice on the expected occurrence of critical terrestrial environment conditions. The services of specialized forecast personnel may be very economical compared to the more expensive vehicle designs that would be required to cope with all terrestrial environment possibilities.

Good engineering judgment must be exercised to apply terrestrial environment requirements to the aerospace vehicle's design analysis. Consideration must be given to the overall vehicle mission and system performance requirements. Knowledge is still lacking on relationships between some of the terrestrial environment parameters that are required as inputs for the design of aerospace vehicles. Also, interrelationships between vehicle parameters and terrestrial environment variables cannot always be clearly defined. Therefore, a close working relationship and team philosophy must exist between the design and operational engineer and the respective organization's terrestrial environment central control point specialists.

In many cases, it is impossible to clearly define the limiting extreme values for a particular terrestrial environment element that may occur during the desired operational lifetime of the vehicle. However, a lower value may be defined so that the probability is small that the lower value will be exceeded during the desired operational lifetime of the vehicle. Risks of launch delay may also be acceptable versus the expense of additional design considerations. Because of these and other considerations, a value that is lower than the extreme may be a more appropriate design requirement. The terrestrial environment specialist is responsible for providing the program manager and chief engineer with pertinent information so they can determine the highest risk value that is feasible for the program. Therefore, it is very important that the aerospace vehicle program manager and the chief engineer have a good understanding of the operational risks due to the selected design terrestrial environment. Terrestrial environment elements may significantly affect multiple areas of an aerospace vehicle's design, and thus operational capabilities, including structure, control, trajectory shaping (performance), heating, takeoff and landing capabilities.

\section{SOME LESSONS LEARNED CONCERNING THE TERRESTRIAL ENVIRONMENT AND AEROSPACE VEHICLE DEVELOPMENT INTERACTIONS}

The NASA Marshall Space Flight Center's Natural Environments Branch and its predecessor organizations have over 50 years of experience in the development and interpretation of terrestrial environment requirements to be used in the design and operation of aerospace vehicles. During this period, a large number of "lessons learned" have formed the basis for the contents of the report "Terrestrial Environment (Climatic) Criteria Guidelines for Use in Aerospace Vehicle Development" (Johnson, 2008) and a conference presentation by the authors (Vaughan and Johnson, 2010). Some of these lessons learned are summarized in the following list.

\section{Wind Vectors Versus Engineering Vector Conventions}

- Background - Flight mechanics use of wind vectors versus conventional meteorological usage. In the case of flight mechanics, the vector is stated in relation to the direction in which force is being applied. However, in meteorology, the wind vector is stated relative to the direction from which the wind force is coming.

- Lesson - The proper interpretation and application of wind vectors is important to avoid a $180 \mathrm{deg}$ error in structural loads and control system response calculations.

\section{Design Requirements, Not Climatology}

- Background - While based on climatology and models, both physical and statistical, terrestrial environment requirements are part of the overall vehicle design effort that is necessary to ensure that mission operational requirements are met. Thus, they must be selected and defined on this basis. Simply making reference to climatology or databases will not produce the desired vehicle design.

- Lesson - Members of the natural environment groups assigned as the control point for inputs to a program must also be part of the vehicle design team and participate in all reviews etc., to ensure proper interpretation and application of natural environment definitions/requirements concerning the overall vehicle design needs. 
Early Input of Natural Environment Requirements Based on Interpretation of Mission Purpose and Operational Expectations

- Background - One needs to develop the natural environment definitions and requirements for a program as soon as possible after knowing the level required for the program's mission. Thus, all of those concerned with the development will have a common base with associated control on changes made to natural environment definitions/requirements and associated vehicle operational impacts.

- Lesson - The definition of natural environment needs for a vehicle that are necessary to meet the mission requirements is important for all of those concerned with the program. This provides visibility to all, especially the program manager and systems engineers, in relation to the impact on the operation of the vehicle and to the natural environment design requirements on the program's mission.

\section{Consistent Input for all Users More Important for} Tradeoff and Design Studies Than Different Inputs on Natural Environment Topic

- Background - The natural environment is one of the key drivers for many of the design efforts on an aerospace vehicle's thermal, structural, and material control. Differences in natural environment inputs used by various design groups can mask critical engineering design inputs if not avoided by consistent and coordinated natural environmental inputs and interpretations for engineering applications.

- Lesson - The need for a focused natural environment group which provides coordinated and consistent environment definitions/requirements/interpretations is key to have all of those involved direct their efforts toward the same inputs, thus contributing to engineering applications that can readily be interpreted from a common base.

\section{Ability to Test New or Changes in Natural}

Environment Requirements Versus Results Important Before Implementing Them as Formal Requirements

- Background - Preliminary assessment of natural environment definitions and requirements must first be accomplished in collaboration with a responsible engineering group in order to identify design drives versus mission requirements. Based on this information, the appropriate natural environment definitions and requirements can be implemented and controlled accordingly.

- Lesson - To avoid problems with the engineering interpretation of natural environment definitions and requirements, the natural environment groups in charge must first interact directly with an appropriate engineering group to ensure proper use and interpretation when formally implemented as part of the overall program requirements.

\section{Maintain Natural Environment Requirements for Design and Operation of Vehicle as Base From Which Other Requirements are Related}

- Background - Taking this action provides a viable and robust operational vehicle capability that will meet the vehicle's mission requirements. Otherwise, a vehicle will be produced with lower operational capability based on natural environment conditions. Natural environment operational requirements can be monitored, and decisions can be made regarding launch operations, etc., or, in case monitoring is not practical or in an emergency, the vehicle will then be functional concerning probable natural environment conditions established on the basis of past records and mission requirements.

- Lesson - Do not design an aerospace vehicle with the natural environment design requirements incorporated as one of the non-nominal inputs and RSS (root sum squared) in the final vehicle design decision.

\section{Natural Environment Elements That Cannot be Monitored Prior to Operational Decision Must be Minimum Risk Level Possible Consistent With Mission Capability Requirements}

- Background - For an aerospace vehicle launch, most terrestrial environment elements can be monitored and thus taken into account before making a launch decision. The same is true for some on-orbit and deep-space spacecraft natural environment operational requirements. In such cases, lower probability of occurrence environments may be considered, consistent with mission requirements, along with subsequent cost savings on design. Vehicle ascent winds through max $\mathrm{Q}$ versus re-entry winds is an example of lower probability (higher risk of occurrence) versus higher probability (lower risk of occurrence) natural environment design requirements 
for a vehicle. However, minimum risk of natural environment requirements must be used for design to ensure operational capability when natural environments cannot be measured or monitored.

- Lesson - It is necessary to carefully analyze the mission requirements relative to vehicle operations and provide the natural environment definitions and requirements accordingly in collaboration with the vehicle program manager to enable the understanding of the implications of environments provided for design.

\section{Maintain Natural Environment Requirements for Design as a Separate Document but Integral to Overall Mission Requirements for Vehicle}

- Background - The natural environment definitions and requirements for the Space Shuttle and Space Station were provided so they could be controlled and available in separate program documents, as part of the overall design requirement documentation. This not only provided direct access for all of those concerned with use of natural environment inputs into design and mission planning but also provided an easy control of inputs. Changes, where required, were readily enabled with the change of one document that had application for all natural environment design requirement inputs to the program.

- Lesson - Each vehicle development program should have only one natural environment definition and requirement document. It should be an integral part of the overall mission requirements for the vehicle design, development, and operations, and be controlled accordingly.

\section{Atmospheric and Space Parameter Analysis Model}

- Background - The ability for a program manager to easily access information on the operational capability impact of a vehicle design change according to the natural environment is an important tool for decision making. In addition, such a tool provides additional insight into mission planning activities, including launch and landing delay probabilities.

- Lesson - Knowledge by mission managers, chief engineers, mission planners, etc. on the availability of an Atmospheric and Space Parameter Analysis Model is a valuable decisionmaking tool and should be used to make the tradeoff decision when the desired operational natural environment is a factor.
Reference Period for Design Statements of Natural Environment Definitions and Requirements Relative to Launch and On-Orbit Operations

- Background - For launch statements on natural environment definitions and requirements, the worst reference month should be used. This provides an operational capability regarding the natural environment that ensures that for any given month, the desired operational capability will be met. Thus, for the worst month reference period, the minimum risk of launch delay due to the natural environment will occur, and all the other months will have less probability of launch delay. The same situation exists for natural environments associated with on-orbit operational capability and deep-space operations. In other words, for these cases the anticipated lifetime in these operational conditions must be taken into account along with the acceptable risk for comprising the mission concerning the natural environment conditions exceeding the design requirements.

- Lesson - All launch terrestrial environment definitions and requirements for the design of a vehicle must be made with respect to the worst month reference period. For natural environments associated with on-orbit and deep-space operations, the anticipated lifetime in these operational conditions must be taken into account along with acceptable risks for operations.

\section{Life-Cycle Cost Estimates and Natural Environment Operational Constraints of Vehicle}

- Background - Once a vehicle has been developed, the constraints relative to operations in the natural environment should be assessed based on the resulting capability of the vehicle. This is the case for launch, on-orbit, and deep-space aspects of the mission. An Atmospheric and Space Environment Parameter Analysis Model can be especially helpful in this regard. The resulting information should be incorporated into the development of the full life-cycle cost estimates and model for the vehicle program.

- Lesson - Consideration needs to be given to the effect of natural environmental constraints on launch vehicle and spacecraft operation when developing full life-cycle cost estimates and models. 


\section{CONCLUSION}

The natural terrestrial environment plays a significant role in the design and operation of aerospace vehicles and in the associated integrity of aerospace systems and elements. This paper has addressed some of the key vehicle and terrestrial environment areas of concern plus some of the "lessons learned" that have been identified and documented over a number of years. Additional lessons learned from an engineering perspective may be found in publications by Blair et al. (2001), Pearson et al. (1996), and Ryan et al. (1996).

\section{REFERENCES}

Bellue, D.G., Boyd, B.F., Vaughan, W.W., Garner, T., Weems, J.W., Madura, J.T. and Herring, H.C. 2006, "Weather Support to the Space Shuttle An Overview: paper Number AIAA-2006-0684", 44 ${ }^{\text {th }}$ AIAA Aerospace Sciences Meeting, Reno, NV.

Blair, J.C., Ryan, R.S., Schutzenhofer, L.A. and Humphries, W.R. 2001, "Launch Vehicle Design Process: Characterization, Technical Integration and Lessons Learned" NASA/TP_2001-210992, NASA Marshall Space Flight Center, AL.

Johnson, D.L., 2008, "Terrestrial Environment (Climatic) Criteria Guidelines for Use in Aerospace Vehicle Development", NASA/ TM-2008-215633, NASA Marshall Space Flight Center, AL, from http://ntrs.nasa.gov/search.jsp?R=20090022159

Pearson, S.D., Vaughan, W.W., Batts, G.W. and Jasper, G.L., 1996, "Importance of the Natural Terrestrial Environment With Regard to Advanced Launch Vehicle Design and Development", NASA TM 108511, NASA Marshall Space Flight Center, AL.
Ryan, R., Blair, J., Townsend, J. and Verderaime, V., 1996, "Working on the Boundaries: Philosophies and Practices of the Design Process", NASA TP-3642, NASA Marshall Space Flight Center, AL.

Vaughan, W.W., 2010, "Guide to Reference and Standard Atmosphere Models", AIAA-G-O03C-2010, American Institute of Aeronautics and Astronautics, Reston, VA, from http://www.aiaa.org

Vaughan, W.W. and Johnson, D.L., 2010, "Aerospace Meteorology: Some Lessons Learned", Proceeding of the $14^{\text {th }}$ Conference on Aviation, Range and Aerospace Meteorology (ARAM), American Meteorological Society, Boston, MA.

Vaughan, W.W., Johnson, D.L., Pearson, S.D. and Batts G.W., 1997, "The Role of Aerospace Meteorology in the Design, Development and Operation of New Advance Launch Vehicles", Proceedings of the Seventh Conference on Aviation, Range and Aerospace Meteorology, American Meteorological Society, Boston, MA. 